\title{
INDIRECT DIODE LASER TREATMENT FOR STAGE 3 RETINOPATHY OF PREMATURITY
}

\author{
D. I. CLARK AND M. HERO \\ Liverporl
}

\begin{abstract}
SUMMARY
Eight infants with stage 3 + retinopathy of prematurity (ROP) were treated using the diode laser through a binocular indirect ophthalmoscope. Two infants with zone I disease were treated prethreshold as soon as the signs of plus disease developed. Successful regression was achieved in all cases, though 3 infants required repeat treatment. All infants were followed up for a minimum of 3 months. Keeler acuity scores were in the normal range in 4 of the 8 infants.

Enhanced survival of very-low-birthweight infants with the introduction of new treatments in neonatal care has increased the incidence of blindness due to retinopathy of prematurity (ROP). ${ }^{1.2}$

Xenon arc photocoagulation for severe ROP was first used in 1968 by Nagata. ${ }^{3}$ Subsequent work with the argon laser confirmed the efficacy of photocoagulation in the management of ROP. ${ }^{4.5}$ Practical limitations of the argon laser delivery system in the treatment of neonates restricted its use and led to the common acceptance of cryotherapy. The American Multicenter Trial for Retinopathy of Prematurity (CryoROP) ${ }^{6}$ confirmed previous clinical impressions by demonstrating a significant reduction in unfavourable outcome in the treatment of stage 3 threshold disease using this method. The advent of a delivery system on the indirect ophthalmoscope, and lightweight portable machines, has made laser treatment a practical alternative to cryotherapy, leading to a re-evaluation of this technique. Argon laser ${ }^{7.8}$ and diode laser ${ }^{9}$ have both been reported as being successful in treating stage 3 threshold disease. In this study the use of the diode laser was evaluated in 8 infants and the 3 month visual outcome described.
\end{abstract}

\section{PATIENTS AND METHODS}

Fifteen eyes of 8 infants were treated with a diode laser

From: Regional Neonatal Unit, Oxford Street Maternity Hospital. Liverpool, UK.

Correspondence to: D. I. Clark, Department of Ophthalmology. Aintree Hospitals. Walton, Rice Lane, Liverpool L9 1 AE, UK. indirect ophthalmoscope between February 1992 and December 1992. Three infants were treated with the Nidek Laser Diode Photocoagulator DC-3000 (Cardiac Services, Dundee); for the remainder a prototype diode laser (Keeler UK, Windsor) was used. Both instruments were loaned from their respective manufacturers as needed. ROP findings were recorded according to the international classification. ${ }^{10}$ All but 2 of the infants were treated at or beyond threshold disease. Threshold disease is defined as 5 or more contiguous (or 8 cumulative) clock-hours of stage 3 in zone I or zone II in the presence of plus disease. Two infants with zone I disease were treated prethreshold as soon as plus disease developed.

All infants of less than 32 weeks gestation and/or with a birthweight of less than or equal to $1500 \mathrm{~g}$ were screened for ROP as previously described. " Six of the infants were nursed in the Regional Neonatal Intensive Care Unit (NICU); 1 was referred for screening and treatment and 1 was referred for treatment from a peripheral unit having been screened by the local ophthalmologist.

Treatment was carried out as soon as was practically possible: within 48 hours in 5 cases and 72 hours in 3 cases. Infants were treated in a converted isolation room off the NICU. The pupils were dilated with $0.5 \%$ cyclopentolate and $2.5 \%$ phenylephrine drops prior to treatment. The infants were treated under a general anaesthetic administered by the neonatologist. They were paralysed with pancuronium, ventilated on an air/oxygen mixture and fentanyl $15 \mu \mathrm{g} / \mathrm{kg}$ was used for analgesia.

Contiguous laser burns were placed just anterior to the ridge and in a scatter fashion throughout the rest of the avascular retina. A scleral depressor (Osbourne and Simmons, UK) designed by D.I.C. was used to facilitate treatment of the peripheral retina. Treatment was carried out using a diode laser with a wavelength of $800 \mathrm{~nm}$ (Nidek) or $810 \mathrm{~nm}$ (Keeler). A 28 dioptre lens was used, producing a spot size of about $600 \mu \mathrm{m}$ diameter. Power sufficient to produce a dull grey/white reaction ranged from 390 to $1100 \mathrm{~mW}$ with a pulse duration of $0.1-0.2$ seconds. 
Post-operatively the infants were kept ventilated until breathing spontaneously. Chloramphenicol ointment q.d.s. and homatropine $1 \%$ eye drops b.d. were administered post-operatively for 3 days. All infants were reviewed 10 days after treatment. If the disease showed signs of regressing the infants were then reviewed fortnightly for up to four visits.

Persistent plus disease was retreated within 48 hours. Retreatment was necessary in 3 infants, 2 because of failure to show signs of regression. These two infants had fill-in laser to the previously applied scatter treatment. The third case had initially shown complete regression but 32 days following treatment neovascular fronds were noted projecting into the vitreous at the vascular/avascular junction (Fig. 1). Cryotherapy was applied contiguously to the avascular retina as the laser was not available.

All infants were reviewed at 3 months from term for assessment of vision, orthoptic status, refraction and fundal examination. Grating acuity scores were recorded using Keeler acuity cards. The acuities were measured with both eyes open as the infants generally objected to occlusion of either eye. The infant in whom only one eye was treated was able to overcome a 10 baseout prism and we have assumed, with fusion present, that the uniocular visions would be equal. Refractions were carried out using $1 \%$ cyclopentolate.

\section{RESULTS}

In this study 8 infants were treated with diode laser. Asymmetrical disease occurred in 1 baby and symmetrical disease in the rest, resulting in 15 eyes being treated. The disease regressed completely in all 15 eyes, though 6 eyes required repeat treatment. The gestational ages ranged from 23 to 26 weeks and the birthweights from 576 to $1160 \mathrm{~g}$ (Table I). The median post-menstrual age at treat-

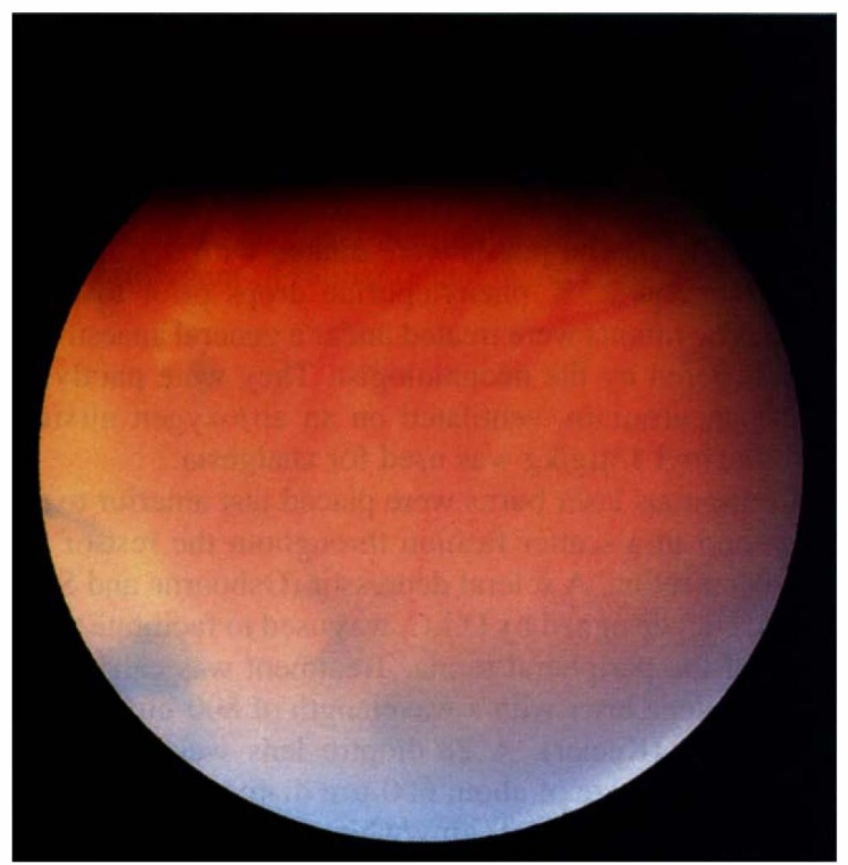

Fig. 1. Case 3. There is recurrence of extraretinal fibrovascular proliferation in the presence of old laser scars ment was 36.3 weeks (range $34-43$ weeks) and the median age at treatment 78 days (range 69-118 days). All the infants demonstrated plus disease and an average of 8 clock-hours of stage 3 was present. However, 2 patients (cases 4 and 8) had prethreshold zone I disease and were treated as soon as plus disease was noted. In 5 eyes the disease was located in anterior/mid zone II; in 6 eyes in posterior zone II (in these cases the disease dipped into zone I temporally); and 4 eyes had zone I disease. The average number of laser applications required was 845 (range 327-1441).

The treatment was successful in all cases. In 2 patients (cases 6 and 7) retreatment was deemed necessary as there was no resolution of plus disease. In case 3 regression was thought to have occurred but 32 days following treatment neovascular fronds were visible extending into the vitreous (Fig. 1). The infant was successfully treated with cryotherapy, though one eye has developed macular ectopia.

Treatment complications were limited to variability of the burn intensity resulting in a rupture of Bruch's membrane associated with a faintly audible 'pop' in 2 patients. No systemic complications occurred during the procedure and the subsequent post-operative course was uneventful.

The grating acuity in 4 infants was at or above the lower limit of normal (Fig. 2). However, in the remaining 4 patients the acuities were below normal. Two infants (cases 2 and 4 ) had acuities of 0.18 and 0.65 cycles/degree respectively; both had had grade 4 intraventricular haemorrhages (IVH). The other 2 infants (cases 5 and 8) would not respond during the vision testing procedure though some level of vision was present; they had had grade 4 IVH and had required ventriculo-peritoneal shunts. The refractive errors ranged from +4.00 to -4.00 dioptres spherical equivalent (SE).

\section{DISCUSSION}

The Multicenter CryoROP Trial has shown the effectiveness of treating threshold ROP using cryotherapy. ${ }^{6}$ The advent of portable lasers delivered through a binocular indirect ophthalmoscope facilitates treatment of this condition, using a modality that is currently used for other ischaemic retinal vascular conditions such as diabetes and vein occlusions. McNamara et al., in a prospective randomised trial of cryotherapy versus argon laser, demonstrated that laser treatment was as effective as cryotherapy. More recently Hunter et $a l .{ }^{9}$ in another randomised trial comparing diode laser with cryotherapy also found laser to be effective, though the numbers were too small for statistical analysis. In our study we have shown that diode laser was successful in causing regression of stage 3 threshold disease and prethreshold zone I disease.

Laser photocoagulation has a number of advantages over cryotherapy. In our own experience of treating infants using either method, laser is tolerated far better with no bradycardias or arrhythmias during the procedure. The treatment of posterior disease is far easier, avoiding the necessity of a conjunctival incision. Scleral indentation is 
Table I. Characteristics of patients treated with diode laser

\begin{tabular}{|c|c|c|c|c|c|c|c|}
\hline $\begin{array}{l}\text { Patient no. } \\
\text { and sex }\end{array}$ & $\begin{array}{c}\text { Gestational age } \\
\text { (weeks) }\end{array}$ & $\begin{array}{l}\text { Birthweight } \\
(\mathrm{g})\end{array}$ & $\begin{array}{l}\mathrm{PMA}^{\mathrm{a}} \text { at } \\
\text { treatment }\end{array}$ & Eye & $\begin{array}{l}\text { Clock-hours } \\
\text { of stage } 3\end{array}$ & $\begin{array}{c}\text { No. of laser } \\
\text { burns }\end{array}$ & Zone \\
\hline $1 \mathrm{M}$ & 26 & 916 & 43 & $\mathrm{~L}$ & 7 & 327 & Ant. zone II \\
\hline $3 \mathrm{~F}$ & 23 & 662 & 34 & $\begin{array}{l}\mathrm{L} \\
\mathrm{R}\end{array}$ & $\begin{array}{l}10 \\
10\end{array}$ & $\begin{array}{l}786 \\
659\end{array}$ & Post. zone II \\
\hline $4 \mathrm{M}$ & 23 & 622 & 35 & $\begin{array}{l}\mathrm{R} \\
\mathrm{L}\end{array}$ & $\begin{array}{l}3 \\
3\end{array}$ & $\begin{array}{l}1263 \\
1078\end{array}$ & Zone I \\
\hline $5 \mathrm{M}$ & 26 & 1160 & 37 & $\begin{array}{l}\mathrm{R} \\
\mathrm{L}\end{array}$ & $\begin{array}{l}7 \\
5\end{array}$ & $\begin{array}{r}1241 \\
713\end{array}$ & Ant. zone II \\
\hline $6 \mathrm{~F}$ & 23 & 576 & 38 & $\begin{array}{l}\mathrm{R} \\
\mathrm{L}\end{array}$ & $\begin{array}{l}8 \\
7\end{array}$ & $\begin{array}{l}749 \\
540\end{array}$ & Post. zone II \\
\hline $7 \mathrm{M}$ & 25 & 732 & 36 & $\begin{array}{l}\mathrm{R} \\
\mathrm{L}\end{array}$ & $\begin{array}{l}8 \\
7\end{array}$ & $\begin{array}{l}722 \\
749\end{array}$ & Mid zone II \\
\hline $8 \mathrm{M}$ & 24 & 672 & 34 & $\begin{array}{l}\mathrm{R} \\
\mathrm{L}\end{array}$ & & $\begin{array}{l}1078 \\
1441\end{array}$ & Zone I \\
\hline
\end{tabular}

R, right; L, left; Ant., anterior; Post., posterior.

a Post-menstrual age at treatment (weeks).

minimal and used mainly to position the globe, and lid and conjunctival oedema is slight compared with cryo-treated infants.

Severe complications have been reported during cryotherapy. ${ }^{6}$ Brown et al. ${ }^{12}$ reported 3 cases of respiratory arrest and 1 of cardio-pulmonary arrest when cryotherapy was carried out under local anaesthesia. Laser treatment is less stressful and relatively pain-free so would be more suitable than cryotherapy for local anaesthesia, though the preference of our paediatricians is to use a general anaesthetic.

The resultant large scars produced by cryotherapy may lead to adverse consequences later in life. Greven and Tasman ${ }^{13}$ reported retinal detachments occurring 3 years after cryotherapy with the tear located at the junction of treated/ untreated retina. They postulate the tear was due to the continued growth of the posterior segment in an eye with severe chorioretinal adhesions. It is not yet known whether such complications will occur in laser-treated eyes but the diode laser burns have been shown to be less destructive than cryotherapy. ${ }^{14}$

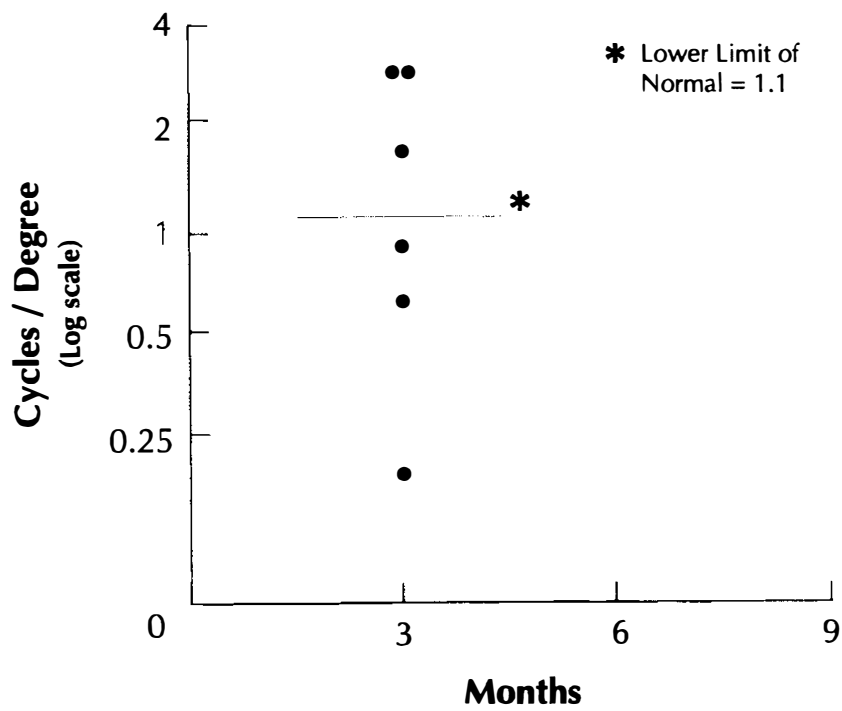

Fig. 2. Keeler acuity at 3 months in diode-laser-treated infants.
Iris clipping has been described as a complication of some types of diode laser but did not occur in our series. ${ }^{15}$ Persistence of the tunica vasculosa lentis is often found in severe posterior ROP and absorption of argon laser by haemoglobin may lead to a lens burn. The longer wavelength of the diode makes this unlikely. No lens burns occurred in our babies. The only complication encountered during laser treatment was rupture of Bruch's membrane in 2 cases. The diode laser requires a consistent working distance to maintain identical burn intensities. ${ }^{15}$ We recommend the laser energy is reduced as the treatment becomes more peripheral to reduce the risk of excessively heavy burns resulting in rupture of Bruch's membrane.

Two infants with zone I disease were treated prethreshold. The results of the CryoROP trial demonstrated a 75\% unfavourable outcome if the disease was located in zone I. ${ }^{6}$ Zone I disease does not progress in the sequential stepby-step manner of ROP occurring more peripherally; rather it is characterised by the development of arteriovenous anastomoses at the distal ends of the vessels ${ }^{16}$ that subsequently join, leading to a $360^{\circ}$ shunt from which fibrovascular proliferation develops. ${ }^{17}$ This rapidly progresses to a retinal detachment. It is the opinion of Tasman ${ }^{18}$ and Sternberg et al. ${ }^{19}$ that waiting until threshold disease develops in zone I before intervening leads to an unacceptably high failure rate. Fleming et $a l^{20}$ have shown that the earlier treatment of 4 infants with posteriorly located disease resulted in complete regression of the disease. We agree that treatment for zone I disease should be given as soon as plus disease develops. Cases 4 and 8 had zone I prethreshold disease at treatment and had a successful outcome.

The visual results of treating stage 3 threshold ROP depend not only on regression of the retinopathy with normal posterior retinal anatomy but also on the neurological status of the infant. In 4 of our cases severe neurological abnormalities were present and in each case the visual responses were reduced. This is in accordance with the results of Luna et al. ${ }^{21}$ who reported a delay in visual 
development in patients with a history of grade 3 or 4 IVH. However, in our other 4 cases with no neurological sequelae the visual acuities were normal. Longitudinal data reported by Birch and Spencer ${ }^{22}$ have suggested that the early grating acuity is predictive of the long-term visual outcome. The CryoROP $3 \frac{1}{2}$ Year Outcome has shown no significant change in the percentage of eyes with a favourable structural outcome at 1 year and $3 \frac{1}{2}$ years, but the functional results were different..$^{23}$ At 1 year the grating acuity showed a $37.8 \%$ reduction in unfavourable outcome but at $3 \%$ years this had fallen to $20.1 \%$. This is because at 1 year lower acuity values are still in the normal range. It is thus too early to predict what the final visual results will be from diode laser treatment.

In conclusion, although the numbers in the study are small, we have demonstrated that diode laser treatment for stage 3 ROP is successful in causing regression of the disease. The procedure is well tolerated, easy to administer and laser is now our preferred method of treatment.

The authors would like to thank the orthoptic and optometry staff at Walton Hospital for their invaluable assistance. We are indebted to Cardiac Services Ltd and Keeler UK Ltd for the loan of the diode lasers. The authors have no financial interests in either of the aforementioned companies, nor the scleral depressor manufactured by Osbourne and Simmons.

Key words: Grating acuity. Indirect diode laser. Retinopathy of prematurity.

\section{REFERENCES}

1. Valentine P, Jackson C. Kalina R, Woodrum D. Increased survival of low birth weight infants: impact on the incidence of retinopathy of prematurity. Pediatrics 1989;84:442-5.

2. Gibson DL. Sheps SB. Hong S, Schecter MT, McCormick AQ. Retinopathy of prematurity-induced blindness: birth weight-specific survival and the new epidemic. Pediatrics 1990;86:405-12.

3. Nagata M. Therapeutic possibility in retrolental fibroplasia in the premature infant with light coagulation. Ganka 1968; 10:719-27.

4. Payne JW, Patz A. Treatment of acute proliferative retrolental fibroplasia. Trans Am Acad Ophthalmol Otolaryngol 1972;76:1234-41.

5. Patz A, Maumenee AE. Ryan SJ. Argon laser photocoagulation: advantages and limitations. Trans Am Acad Ophthalmol Otolaryngol 1971:75:569-79.

6. Cryotherapy for Retinopathy of Prematurity Cooperative Group. Multicenter trial of cryotherapy for retinopathy of prematurity: preliminary results. Arch Ophthalmol 1988; 106:471-9.

7. Landers MB, Toth CA. Semple HC. Morse LS. Treatment of retinopathy of prematurity with argon laser photocoagulation. Arch Ophthalmol 1992:110:44-7.

8. McNamara JA, Tasman W, Brown GC, Federman JA. Laser photocoagulation for stage 3+ retinopathy of prematurity. Ophthalmology 1991:98:576-8().

9. Hunter DG, Repka MX. Diode laser photocoagulation for threshold retinopathy of prematurity. Ophthalmology 1993; 100:238-44.

10. Committee for the Classification of Retinopathy of Prematurity. The international classification of retinopathy of prematurity. Arch Ophthalmol 1984:102:1130-4.

11. Clark DI, O’Brien C, Weindling AM, Saeed M. Initial experience of screening for retinopathy of prematurity. Arch Dis Child 1992;67:1233-6.

12. Brown GC. Tasman W. Naidoff M. Schaffer DB, Quinn G, Bhutani VK. Systemic complications associated with retinal cryoablation for retinopathy of prematurity. Ophthalmology 1990:97:855-8.

13. Greven CM, Tasman W. Rhegmatogenous retinal detachment following cryotherapy in retinopathy. of prematurity. Arch Ophthalmol 1989:107:1017-8.

14. Nissenkorn I, Kremer I. Ben Sira I. Cohen S. Garner A. A clinicopathological case of retinopathy of prematurity treated by peripheral cryopexy. Br J Ophthalmol 1984;68: 36-41.

15. Woon WH. Ifytche TJ, Hamilton AMP, Marshall J. Iris clipping of a diode laser beam when performing retinal photocoagulation. Br J Ophthalmol 1991;75:386-90.

16. Uemura Y. Current status of retrolental fibroplasia: report of the joint committee for the study of retrolental fibroplasia in Japan. Jpn J Ophthalmol 1977:21:366--78

17. Tasman W. Zone I retinopathy of prematurity. Arch Ophthalmol 1985;103:1693-4.

18. Tasman $\mathrm{W}$. Threshold retinopathy of prematurity revisited. Arch Ophthalmol 1992;110:623-4.

19. Sternberg P, Lopez PF, Lambert HM, Aaberg TM, Capone A. Controversies in the management of retinopathy of prematurity. Am J Ophthalmol 1992;113:198-202.

20. Fleming TN, Runge PE. Charles ST. Diode laser photocoagulation for prethreshold, posterior retinopathy of prematurity. Am J Ophthalmol 1992:1 14:589-92.

21. Luna B. Dobson V. Biglan AW. Development of grating acuity in infants with regressed stage 3 retinopathy of prematurity. Invest Ophthalmol Vis Sci 1990;31:2082-7.

22. Birch EE, Spencer R. Visual outcome in infants with cicatricial retinopathy of prematurity. Invest Ophthalmıl Vis Sci 1991;32:410-5.

23. Cryotherapy for Retinopathy of Prematurity Cooperative Group. Multicenter trial of cryotherapy for retinopathy of prematurity: $31 / 2$ year outcome - structure and function. Arch Ophthalmol 1993;111:339-44. 